\title{
Verbal manifestations of metacognitive and social cognitive operations in patients with schizophrenia who received metacognitive training
}

\author{
Zita Fekete $^{1,2}$ (D) Edit Vass $^{3} \cdot$ Martina Farkas-Pócs $^{4} \cdot$ Ramóna Balajthy $^{5} \cdot$ Ildikó Szabó Kuritárné $^{1}$
}

Accepted: 25 January 2022

(c) The Author(s) 2022

\begin{abstract}
The study investigates with inductive content analysis the verbal manifestations of schizophrenia patients, their utterances within the theory of mind modules of Metacognitive Training. Participants were recruited via psychiatrists' verbal referrals. Four small groups were formed, two of which consented to the audio recording of their sessions. Only the sessions of these two groups of five and four patients respectively were investigated. As two participants dropped out, the verbalisations of seven participants were eventually analysed. All patients had schizophrenia diagnosis (mean age: 43 years, male: two, female: five). The verbal contents were transcribed, then two independent coders did the categorisation of the content; investigator triangulation ensured the reliability and validity of the study. As a result, a five-level hierarchy of cognitive operations was revealed in a bottom-up way. Patients attempted to interpret not only facial expressions but expressive movements, too, during emotion recognition. When deducing the state of others, patients sought contextual information; moreover, the burden of the illness and stigmatisation became easy to share. No signs of awareness of the consequences of the inferred states were found regarding future adjustment. Our hierarchical structure was consistent with related literature, and the specificities of cognitive operations of participants were also revealed.
\end{abstract}

Keywords Schizophrenia $\cdot$ Metacognition $\cdot$ Social cognition $\cdot$ Metacognitive Training $\cdot$ Content analysis

\section{Introduction}

Schizophrenia is a severe psychiatric illness of a pervasive and progressive nature. Nearly $1 \%$ of the world's population is affected by this highly disabling condition
(McGrath et al., 2008). Core symptoms of the disorder are hallucinations and delusions accompanied in many cases by symptoms of disorganization (e.g., disorganized speech, disorganized behavior), negative symptoms (e.g., abulia, affective decoloration), and

\section{Zita Fekete}

fekete.zita@med.unideb.hu

Edit Vass

vass.edit@med.semmelweis-univ.hu

Martina Farkas-Pócs

tinapocs@gmail.com

Ramóna Balajthy

ferenczi.rami@gmail.com

Ildikó Szabó Kuritárné

kuritarne.ildiko@med.unideb.hu

1 Faculty of Medicine, Institute of Behavioural Sciences, University of Debrecen, Móricz Zsigmond blvd. 22.,

4032 Debrecen, Hungary
Doctoral School of Health Sciences, University of Debrecen, Egyetem sq. 1., 4032 Debrecen, Hungary

3 Faculty of Medicine, Department of Psychiatry and Psychotherapy, Semmelweis University, Balassa str. 6., 1083 Budapest, Hungary

4 Pest County Pedagogical Service, Kálvin sq. 4/B., 2310 Szigetszentmiklós, Hungary

5 Department of Psychiatry and Psychotherapy, Szabolcs-Szatmár-Bereg County Hospitals and University Teaching Hospital, Jósa András Teaching Hospital, 4400 Nyíregyháza, Szent I. str. 68., Hungary 
cognitive impairments. The biological and environmental factors underlying the disorder have been intensively researched (van Os \& Kapur, 2009), and this has been complemented in the past decades by research on cognitive function. The attention of the researchers focused primarily on neuropsychological impairments (Fioravanti et al., 2005), but recently social cognitive (AbuAkel, 1999; Brüne, 2005; Firth, 2015; Herold et al., 2002; Penn et al., 2002; Stratta et al., 1999, 2000) and metacognitive (Lysaker et al., 2013a, b, 2014) impairments have become an emerging field in schizophrenia research. Impairments of metacognitive and social cognitive domains are important factors along with the development and maintenance of the symptoms and poor functioning. These impairments lead to misinterpretation and misattribution of social aspects, which can contribute to the development of not only positive symptoms, including delusions and hallucinations, but also negative symptoms, such as social withdrawal, which will subsequently prevent appropriate adaptation (Lysaker et al., 2015a; Penn et al., 2008). In the following sections, we summarise the characteristics of metacognition and social cognition, including their subdomains.

The term metacognition first occurred in the literature of learning (Flavell, 1979), and was defined as thinking about thinking or "cognition about cognitive phenomena" (p. 906). In this sense, metacognition can be considered a complex cognitive phenomenon that includes awareness of discrete cognitive functions (e.g., memory) as well as synthetic processes (e.g., developing comprehensive representations of the self and others) (Lysaker et al., 2013a). It requires crucial functions involved in monitoring and controlling mental processes (Flavell, 1979; Nelson, 1996). The most often assessed subdomains of metacognition are self-reflectivity, understanding others' mind, decentration, and mastery (Lysaker et al., 2005, 2007). The subdomain of self-reflectivity refers to the comprehension of one's self, while understanding others' mind involves comprehension of others' mental state. Decentration describes the ability to see others as individuals with their own cognitive contents and perspectives, independent of our own; while mastery refers to the ability to use metacognitive knowledge in order to cope with mental issues (Lysaker et al., 2005, 2007). In this sense, metacognition can be considered as an umbrella concept with its monitoring and controlling function including social cognition, due to the fact that metacognition has an observing and corrective function over it (Lysaker, Vohs, et al., 2013). Social cognition refers to cognitive operations like perceiving and interpreting our own and others' mental states (Penn et al., 2008), and involves the following subdomains: emotion recognition, Theory of Mind (ToM), attributional style, and social perception (Pinkham et al., 2014). The term emotion recognition refers to perceiving emotions (Green et al., 2008). ToM is the ability to infer mental states to others; attributional style is the way how individuals explain the causes of events and interactions; and social perception refers to the interpretation of social cues (Pinkham et al., 2014). Other researchers suggest differentiating social perception from social knowledge: social perception refers to the identification of social rules, cues and context, and social knowledge involves awareness of all the aforementioned factors (Green et al., 2008).

Although literature data suggest a partial overlap between metacognition and social cognition, Lysaker and coworkers (Lysaker et al., 2013c) found evidence for their being independent from each other.

Expanding our knowledge is important because impairments of the aforementioned cognitive functions lead to developing and maintaining symptoms of schizophrenia (Lysaker et al., 2015a; Penn et al., 2008). In addition, metacognitive and social cognitive deficits are closely related to poor social outcomes (Hofer et al., 2009; Irani et al., 2012). In the last decades research led to the development of training programs like the Metacognitive Training (MCT) (Moritz \& Woodward, 2007), which aims to improve the metacognitive and social cognitive abilities of patients with schizophrenia (Vass et al., 2018). These training programmes are based on empirical research findings, the results of which draw our attention to the importance of the schizophrenia-related functions discussed above. Research uses a predominantly quantitative methodology (e.g., ArnonRibenfeld et al., 2017; Savla et al., 2013). In line with the predominance of quantitative studies, there is a wide range of assessment tools available. However, most of these tools in social cognition and metacognition are only able to measure circumscribed parts of these complex phenomena as they employ predefined questions, tasks, and scoring methods. In contrast, studies of verbal content provide insights into a broader spectrum of underlying cognitive processes (Brown \& Lenneberg, 1954).

Our current research studies in a qualitative way the verbal manifestations of patients with schizophrenia captured while they were doing their best to solve metacognitive and social cognitive tasks of MCT in a group setting. Due to the particularity of the tasks in MCT, the verbalisations produced by group members are quite noteworthy as they can be considered as products resulting from participants' cognitive operations (Brown \& Lenneberg, 1954). Therefore, we studied verbal manifestations with the help of conventional content analysis to map the patients' metacognitive and social cognitive operations in a bottom-up way. We focused not on the correctness of their answers but on the nature of their verbal manifestations instead.

Our goal was to find answers to the following questions: a) whether the qualitative study made on the verbal contents 
of patients with schizophrenia while they were solving metacognitive and social cognitive tasks enables us to describe and structure the characteristics of cognitive operations; $b$ ) whether the results of the qualitative study are consistent with recent literature.

The manuscript was prepared in line with the COREQ guideline (Tong et al., 2007).

\section{Method}

\section{Design and Applied Training Method}

The hybrid method of MCT (Moritz \& Woodward, 2007) is based on cognitive-behavioural therapeutic considerations, and it integrates the principles of psychoeducation and cognitive remediation. MCT is a structured group training program built up in a modular way, where educational material and targeted social cognitive and metacognitive tasks are displayed on PowerPoint slides. The training is conducted in small groups. It contains 8 modules in 2 cycles ( 16 modules altogether), where each module aims to improve a specific cognitive phenomenon (attributional style with two modules in a cycle, jumping to conclusions, belief inflexibility, ToM with two modules in a cycle, overconfidence in memory errors, and depressed mood), plus two extra modules (selfesteem and stigma), which we eventually decided not to use because they had not been translated by the time of the study. Each module has a similar structure: they begin with the introduction of the actual domain, then the importance of the domain is highlighted with the help of educational elements. The task series contain exercises developed particularly for the given cognitive domain (e.g., details of pictures of people with expressive faces for emotion recognition; short cartoon stories for identifying characters' intentions, beliefs, or thoughts).

The efficacy and applicability of MCT in schizophrenia have been demonstrated in more meta-analyses based on the results of several randomised controlled trials (e.g., Eichner \& Berna, 2016; Liu et al., 2018; Lopez-Morinigo et al., 2020a, b).

The applied MCT is a widely used training method in schizophrenia. It has been translated into 37 languages by now, and one of these is Hungarian. The training material (except for the extra modules) had been translated into Hungarian before the study was carried out. The training contains 1,512 PowerPoint slides translated from German by a clinical psychologist, and checked and corrected by another clinical psychologist. During this process, some of the tasks were adapted to our culture. Then the translated training was carried out with a patient diagnosed with schizophrenia, and the experience gained there was used for further adaptation. Subsequently, two further clinical psychologists conducted a training with a small group of patients diagnosed with schizophrenia, each in a different group. Their feedback was also used for the further adaptation of the training material to our own language and culture.

Between 2018 and 2020 four MCT groups were set up in the Department of Psychiatry of the Jósa András University Teaching Hospital in Nyíregyháza, Hungary. Most of the participants attended the training on the advice of their treating psychiatrist. The aim of the training was twofold. Primarily, MCT was applied as part of our patients' treatment; therefore, their grouping was done exclusively on the basis of the order in which they applied for MCT. For the sake of effectiveness, we formed small groups of 4-6 patients, which eventually resulted in four groups.

Secondly, we expected the verbal material of the sessions to be able to provide an appropriate platform to study the cognitive operations behind the verbalisations of the participants; this is why we decided to study our patients' utterances. Accordingly, in groups where participants agreed to have their verbal material studied, audio recordings were made. We only audio recorded the sessions where each and every group member consented to it. Unfortunately, merely two of the four groups contributed to the recording. Subsequently, the present study analyses the verbal contents of these two small groups only.

Participants of the groups were patients diagnosed with schizophrenia, i.e., the groups were homogenous regarding the diagnoses of the participants. Both groups received standard MCT.

The training lasted for four months (16 modules, one module/week) in both groups. All training sessions were audio-recorded, then verbatim transcribed. However, we only used the four modules of Theory of Mind (a total of eight modules in the two small groups, i.e., eight sessions) for content analysis, as their complexity can provide deep enough insight into social cognitive and metacognitive operations at the same time.

The transcribed verbal contents of the groups were merged into one body text serving as the only material for content analysis.

\section{Participants}

The participants were outpatients with schizophrenia (DSM-5). All of them were in the remissive phase of the illness, and were receiving antipsychotic treatment. Group members were recruited via written leaflets and verbal referrals of the patients' psychiatrists. Psychiatrists recommended participation to patients whose medical history was well-established, and who fulfilled the diagnostic criteria of schizophrenia (DSM-5). We relied on clinical diagnosis issued by a psychiatrist. 
One of the analysed training groups included five, while the other included four participants, and the first author, a licensed clinical psychologist and psychotherapist, acted as a trainer in both groups. The trainer had no previous therapeutic contact with the participants. One of the patients (female; 37 years old; spent 12 years in illness, and was hospitalised due to schizophrenia 12 times) was offered a job in a distant part of the city after the first session; subsequently, she dropped out. Another group member (female; 30 years old; spent 9 years in illness, and was hospitalised due to schizophrenia 15 times) could not participate regularly due to her physical condition (not related to her mental state). Consequently, we analysed the verbal contents of seven participants $(N=7)$, who were aged between 35 and 59 (mean $=43, \mathrm{SD}=8.66)$. Two of them were male, and five were female. As regards educational attainment, one of the participants received primary education, five patients had secondary school certificate, and one of them graduated from university. Six members were part-time employees (doing supported work for psychiatric patients), and one was employed full-time. None of them was married or had a romantic relationship at the time of the training. The mean duration of schizophrenia was 15 years $(\mathrm{SD}=7.12)$, and the patients were hospitalised due to the illness 5.43 times on average $(\mathrm{SD}=3.59)$ (Table 1). None of the participants suffered from any relevant comorbid psychiatric or somatic disease.

\section{Ethics}

Ethical approval was granted by the Hungarian Scientific Ethical Committee for Research, and the study got approval number 42520-2/2018/EKU. All participants were informed in writing about the aims and methods of the study. The participants took part voluntarily in the study, and they were assured for anonymity and the opportunity to end the study any time without losing any benefits of their ongoing treatment. The participants were informed about the audio-recording of the group sessions, then they signed a written informed consent form. The digital audio recordings and verbatim transcriptions of the sessions were encrypted.

\section{Data Collection}

In the analysed ToM modules, participants have to infer mental states to the protagonist(s) of short cartoon stories or photos, or they have to conclude the possible future behaviour of the person in the picture. In some tasks, group members received pre-set options, while in other tasks they did not; each task, however, could only be solved by mobilising the patients' metacognitive and social cognitive abilities (Moritz \& Woodward, 2007). Participants were encouraged to express their opinions about the possible solutions of the tasks, and discuss them in the group. They also had the opportunity to share their own related experiences. Accordingly, the modules provided appropriate verbal content for our research goals regarding the study of verbal manifestations of cognitive operations.

We analysed the verbal contents of eight group sessions. The mean duration of sessions was $65.1 \mathrm{~min}(\mathrm{SD}=13.87, \Sigma$ : $521 \mathrm{~min}$, minimum: $44 \mathrm{~min}$, maximum: $81 \mathrm{~min}$ ). The verbatim transcribed verbal manifestations of the groups were merged into one body text (50,915 words, 211 pages). The verbal contents of the trainer were not removed from the transcripts: they were only used as context, not as an object of content analysis. The contents of the two participants who dropped out were removed from the transcripts. No software was used for the analysis.

\section{Data Analysis}

For data analysis, we applied conventional content analysis (Hsieh \& Shannon, 2005), in the framework of which we made use of inductive category development to avoid biases rooted in theoretical preconceptions, and to gain an in-depth and comprehensive understanding of the studied complex experiences. The content analysis process was carefully designed to avoid biases rooted in methodological shortcomings, and thus ensure the internal validity of the study.
Table 1 Demographic data of study participants

\begin{tabular}{llllllll}
\hline Participant & Gender & Age & Education & Employment & Marital status & $\begin{array}{l}\text { Hospital- } \\
\text { isations }\end{array}$ & $\begin{array}{l}\text { Years } \\
\text { in ill- } \\
\text { ness }\end{array}$ \\
\hline P1 & female & 36 & secondary school & part- time & divorced & 6 & 9 \\
P2 & female & 45 & primary school & part- time & single & 3 & 12 \\
P3 & female & 35 & secondary school & part- time & single & 2 & 14 \\
P4 & female & 38 & secondary school & part- time & single & 4 & 15 \\
P5 & female & 59 & university & part- time & single & 5 & 28 \\
P6 & male & 49 & secondary school & part- time & divorced & 13 & 20 \\
P7 & male & 39 & secondary school & full- time & single & 5 & 7 \\
\hline
\end{tabular}


The rigour of the study was ensured by following the recommendations of Mays and Pope (1995). To ensure the reliability of the analysis, two independent coders carried out the coding, and a third independent reviewer was invited to check the coded transcriptions and suggest modifications when needed. We accepted the suggestions when at least one of the two coders agreed with the peer reviewer ( $2 / 3$ majority). All modifications were recorded. This investigator triangulation (Renz et al., 2018) was used to ensure the validity of the study. For further support of validity, the verbal material of more than one training group was analysed, as mentioned previously. Moreover, two of the three investigators were hardly familiar with the theory of metacognition and social cognition, so that they would rely on the information extractable from the text rather than look for structures on the basis of their theoretical knowledge.

Data analysis was executed in three main steps (Fig. 1):

(1) Two coders (ZF and MFP) read the transcripts independently, and took notes to become familiar with the whole text and gain a detailed picture of participants' verbal contents. The maximum saturation was reached when it was not possible for the coders to further differentiate the material of the first group. To ensure the standardisation of data analysis and the extracted data, all the categories to be used were closely defined, and prototypical examples were assigned to the individual definitions. After that, the transcripts were coded independently. As a next step, the ambiguously coded contents were discussed, and modifications were made where necessary. Codes were modified in 621 (out of
$2,959)$ units of the identified verbal contents. Then the third investigator $(\mathrm{RB})$ received the definitions of the categories to check the coded transcripts; she suggested modifications in 26 cases. Eventually, altogether 16 changes were made (by $2 / 3$ majority).

(2) The text has been re-read by the two coders (ZF and MFP) to set up the nodes resulting from the categories with cohesive content. Then, both coders extended their coding scheme onto each identified node, and re-scanned and re-coded the text using the extended system. As a next step, the coders met to discuss the ambiguously coded contents, as well as the ambiguously named nodes. Modifications were carried out in the naming of the nodes in seven cases, and coding was modified in 15 cases. Definitions of the nodes were formulated using the common elements of the descriptions used for the categories. The third investigator (RB) received the node names and their definitions, and reviewed the re-coded transcripts, which resulted in recommending the modification of one of the nodes only (The proposal was adopted by a $2 / 3$ majority of the investigators). The coded text was re-screened relying on the modified node.

(3) All the three coders re-read the text, then worked together to identify themes encompassing nodes with cohesive contents. For developing the definitions of the themes, the definitions of the nodes were used; a $2 / 3$ majority was needed for a theme to be accepted. Then the two coders (ZF and MFP) re-coded the text in a way similar to the previous steps. Finally, the third

Fig. 1 Data analysis flowchart

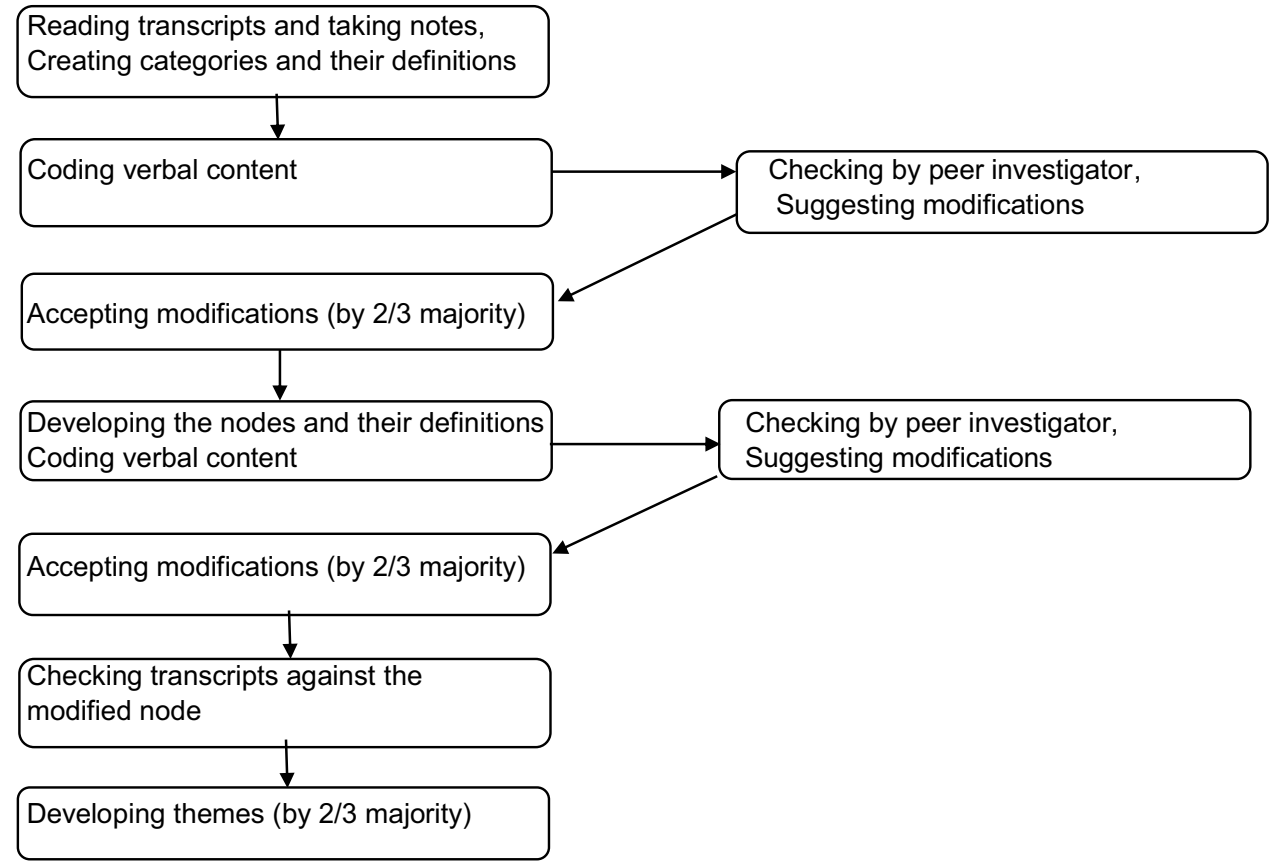


investigator $(\mathrm{RB})$ reviewed the coded transcripts; no modifications were suggested.

Using the method described above, we were able to organise the patients' verbal contents into a hierarchical structure. Eventually, this structure developed in a bottomup way was compared to the theoretical model of metacognition and social cognition.

To ensure the differentiation between social cognitive and metacognitive phenomena, we relied on the work of Flavell (1979) and Nelson (1996); verbal contents were considered as manifestations of metacognitive processing when we could unequivocally detect monitoring and controlling operations, or signs of awareness of participants' own or others' cognitive contents. We regarded other social-related contents as manifestations of social cognitive phenomena.

\section{Results}

As a result of ordering contents into categories, nodes, and themes, and comparing them against literature, the analysed verbal expressions confirmed a five-level hierarchical structure with 35 categories on the lowest level, 18 nodes on the second level, and 10 themes on the third level. On the fourth, penultimate level of the hierarchical structure, we saw subdomains of metacognition and social cognition, whereas on the top of the hierarchy we found metacognition and social cognition (Fig. 2). In other words, it was possible to make detailed observations on the participants' way of thinking through their speech, and gain information on the hierarchy of domains of cognitive operations. Furthermore, the identified themes and their building blocks matched the theoretical constructions of metacognition and social cognition based on the results of quantitative studies (Table 2).
In the following section, a review of our findings is presented along the identified themes and theoretical frameworks. The expressions in italics are citations from our patients' verbal contents, typical of the particular topic.

\section{Metacognition}

\section{Understanding Others' Mind}

Theme 1. Knowledge of Cognitive Perspectives According to our findings, participants monitored and regulated their thinking to form complex knowledge about their own and others' cognitive contents, perspectives, and operations (Node 1: "Monitoring of Cognitive Perspectives" built from the categories of "Perspective" and "Different Perspectives"). Participants recognised that other people may have perspectives different from theirs (Node 2: "Regulation of Cognitive Perspectives" built from the categories of "Overruling a Perspective" and "Agreement with Others' Perspectives").

Patient 5: "If you're in a situation where you feel uncertain, you see the situation accordingly. So, the emotions are this decisive, even if thinking is meant." (Cycle 1, Module 4)

Patient 2: "Look, this is the difference between us. You think that such a situation isn't a fight, but I'm at war with everyone." (Cycle 1, Module 6)

\section{Self-reflection}

Theme 2. Self-reflection We managed to identify several verbal contents reflecting participants' own internal traits and
Fig. 2 Five-level hierarchical structure of the observed verbal manifestations of cognitive operations

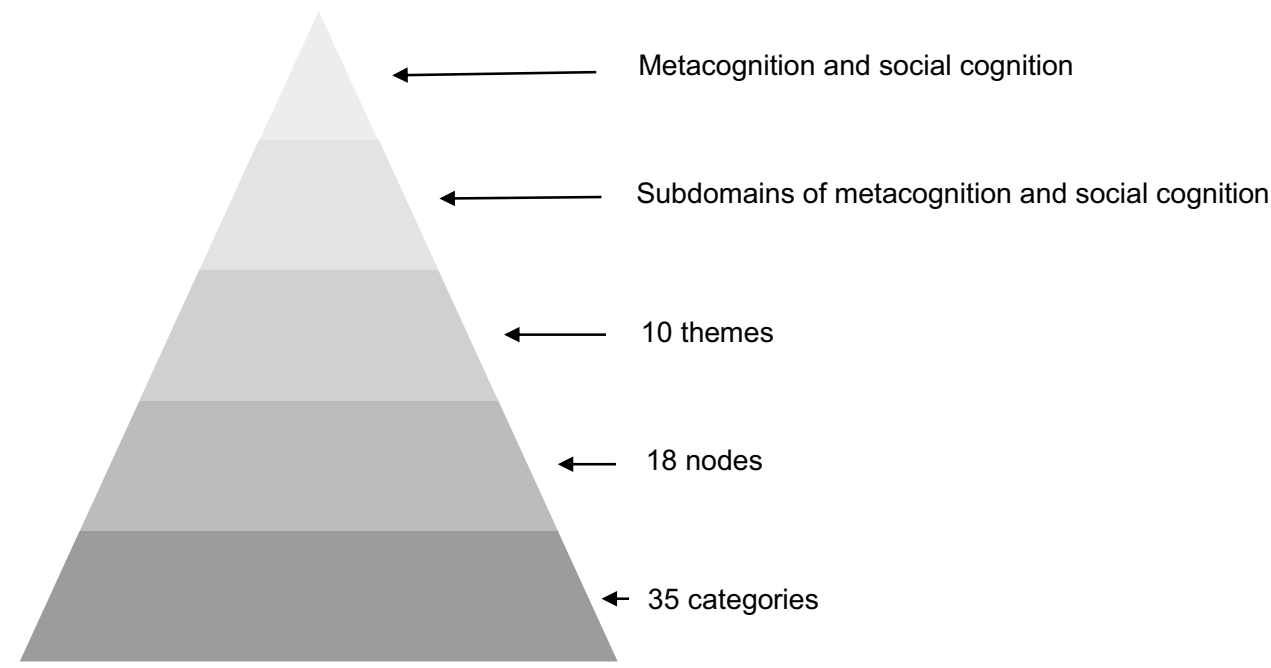


Table 2 The hierarchical structure of categories, nodes, and themes with the appropriate theoretical terms of the literature

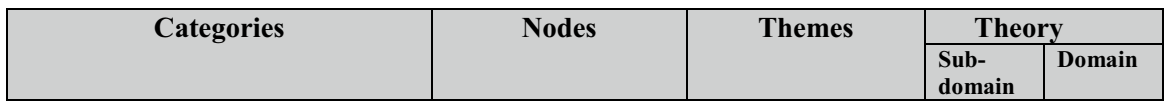

\begin{tabular}{|c|c|c|}
\hline Perspective & \multirow{2}{*}{\begin{tabular}{|l|} 
1. $\begin{array}{l}\text { Monitoring of } \\
\text { Cognitive } \\
\text { Perspectives }\end{array}$ \\
\end{tabular}} & \multirow{4}{*}{$\begin{array}{c}\text { Theme 1: } \\
\text { Knowledge of } \\
\text { Cognitive } \\
\text { Perspectives }\end{array}$} \\
\hline Different Perspectives & & \\
\hline Overruling a Perspective & \multirow{2}{*}{$\begin{array}{ll}\text { 2. } & \text { Regulation of } \\
\text { Cognitive } \\
\text { Perspectives }\end{array}$} & \\
\hline $\begin{array}{lll}\text { Agreement with } & \text { Others' } \\
\text { Perspectives } & & \\
\end{array}$ & & \\
\hline $\begin{array}{l}\text { Awareness of One's Own } \\
\text { Intrinsic Traits }\end{array}$ & \multirow{2}{*}{$\begin{array}{l}\text { 3. Awareness of } \\
\text { One's Own } \\
\text { Internal } \\
\text { Characteristics }\end{array}$} & \multirow{2}{*}{$\begin{array}{l}\text { Theme 2: } \\
\text { Self-reflection }\end{array}$} \\
\hline Self-criticism & & \\
\hline
\end{tabular}

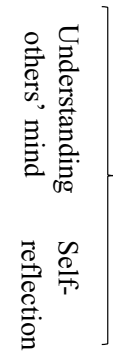

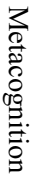

\begin{tabular}{|c|c|c|}
\hline Internal Characteristics & 4. Internal & \\
\hline Internal State & Characteristics & Theme 3: \\
\hline Praising Others & $\begin{array}{l}\text { 5. Communicating } \\
\text { Ideas about } \\
\text { Others' } \\
\text { Characteristics }\end{array}$ & $\begin{array}{c}\text { Ideas about } \\
\text { Others' Internal } \\
\text { Characteristics }\end{array}$ \\
\hline $\begin{array}{l}\text { One's Knowledge about the } \\
\text { Situation of the Protagonist }\end{array}$ & \multirow{3}{*}{$\begin{array}{l}\text { 6. Knowledge } \\
\text { about Others' } \\
\text { Ideas }\end{array}$} & \multirow{5}{*}{$\begin{array}{l}\text { Theme 4: } \\
\text { Knowledge about } \\
\text { Others' Mind }\end{array}$} \\
\hline $\begin{array}{l}\text { One's Ideas of Others' Judgement } \\
\text { about Him/Her }\end{array}$ & & \\
\hline $\begin{array}{l}\text { Others' Judgement about the } \\
\text { Participant }\end{array}$ & & \\
\hline $\begin{array}{l}\text { The Protagonist's Knowledge } \\
\text { about the Situation }\end{array}$ & \multirow{2}{*}{$\begin{array}{l}\text { 7. Knowledge } \\
\text { about Others' } \\
\text { Ideas } \\
\text { Regarding a } \\
\text { Third Part of } \\
\text { the Context }\end{array}$} & \\
\hline $\begin{array}{l}\text { The Protagonist's Knowledge } \\
\text { about Others' Internal State }\end{array}$ & & \\
\hline
\end{tabular}

\begin{tabular}{|c|c|c|}
\hline Gesture & \multirow{2}{*}{$\begin{array}{ll}\text { 8. } & \text { Expression of } \\
\text { Emotions }\end{array}$} & \multirow{3}{*}{$\begin{array}{l}\text { Theme 5: } \\
\text { Emotion } \\
\text { Recognition }\end{array}$} \\
\hline Facial Expression & & \\
\hline Emotional State & $\begin{array}{l}\text { 9. Naming } \\
\text { Emotional } \\
\text { States }\end{array}$ & \\
\hline
\end{tabular}

\begin{tabular}{|l|c|c|}
\hline Naming & $\begin{array}{c}\text { 10. Objects } \\
\text { Surrounding } \\
\text { the Social } \\
\text { Context }\end{array}$ & $\begin{array}{c}\text { Theme 6: } \\
\text { Non-social } \\
\text { Context }\end{array}$ \\
\cline { 1 - 2 } Social Classification & $\begin{array}{c}\text { 11. Ideas about the } \\
\text { Social Context }\end{array}$ & $\begin{array}{c}\text { Theme 7: } \\
\text { Social Context }\end{array}$ \\
\cline { 1 - 2 } Background & 12. Social Cues & Cues of a Situation
\end{tabular}

Further themes that emerged

\begin{tabular}{|c|c|c|}
\hline Inappropriate Verbalisation & $\begin{array}{c}\text { 13. Inappropriate } \\
\text { verbalisation }\end{array}$ & $\begin{array}{c}\text { Theme 8: } \\
\text { Inappropriate } \\
\text { Verbalisation }\end{array}$ \\
\hline
\end{tabular}

\begin{tabular}{|l|l|l|}
\hline Illness & \multirow{2}{*}{ 14. Illness } & \multirow{2}{*}{$\begin{array}{c}\text { Theme 9: } \\
\text { Illness }\end{array}$} \\
\cline { 1 - 1 } Medication & & \\
\hline Symptoms & 15. Stigma & \\
\hline
\end{tabular}

\begin{tabular}{|l|c|c|}
\hline Response & 16. Response & \\
\cline { 1 - 2 } Uncertainty of Response & $\begin{array}{r}\text { 17. Aids to solve } \\
\text { training tasks }\end{array}$ & $\begin{array}{r}\text { Theme 10: } \\
\text { Training }\end{array}$ \\
\cline { 1 - 1 } Referencing & $\begin{array}{r}\text { Lack of Information } \\
\text { Communication of Knowledge } \\
\text { applicability of } \\
\text { the training }\end{array}$ & \\
\cline { 1 - 2 } Application of the Training & \\
\cline { 1 - 2 } Praising the Training Material & & \\
\cline { 1 - 2 } Criticising the Training Material & &
\end{tabular}


states, even in the form of self-criticism (Node 3: "Awareness of One's Own Internal Characteristics" built from the categories of "Awareness of One's Own Intrinsic Traits" and "Self-criticism").

Patient 3: "We have to learn not to criticise others so easily. Now, I'm a fine one to talk...the great critic!" (Cycle 1, Module 4)

In these verbal contents signs of monitoring and controlling operations, or signs of awareness on one's own or others' cognitive contents, in other words, manifestations of metacognitive functioning, were found. Accordingly, Themes 1 and 2 are considered as expressions of metacognitive operations.

Although signs of metacognitive monitoring operations were seen, no signs of awareness of the consequences or effects of the verbalised states, traits, or perspectives could be detected in the transcripts (e.g., Why should not we criticise others? What can it lead to? What would be a more appropriate behaviour, and what consequences would that have?).

\section{Social Cognition}

\section{Theory of Mind}

Themes 3 and 4. Ideas about Others' Internal Characteristics and Knowledge about Others' Mind Patients draw conclusions from, or formed impressions about the essential trait-like characteristics of others (Nodes 4 and 5: "Internal Characteristics" and "Communicating Ideas about Others' Characteristics"). These assumptions often contributed to deducing others' mental states. In other words, guided processing on ToM tasks helped people with schizophrenia in first-order theory of mind processing (Node 6: "Knowledge about Others' Ideas"), which requires the ability to infer mental states to others (Brüne, 2005).

In addition, these assumptions contributed to the integration of their ideas about the protagonists' minds with the information rooted in the social context.

Patient 1: "He's drunk, isn't he?"

Patient 4: “No, I think he's pompous. He thinks he's God's gift to the world, and he wants to show it to the girl." (Cycle 1, Module 4)

Apart from the verbal manifestations of first-order ToM operations, verbal contents identified as a result of higherorder ToM processes could also be detected. Higher-ordered ToM operations require the ability to go beyond the literal meaning of others' uttered words (e.g., irony or cheating) (Brüne, 2005), and require complex and recursive metarepresentational operations (Valle et al., 2015). These contents were classified into Node 7: "Knowledge about Others' Ideas Regarding a Third Part of the Context". Our patients developed assumptions of others' (regarding the protagonist or people in other patients' lives) knowledge about a third person's mental state.

Patient 3: "In my opinion, the man with a moustache thinks that the bald man took revenge on him by destroying his car because he was listening to music too loudly." (Cycle 1, Module 6)

It is important to note again that we did not examine the correctness of the drawn conclusions but only the nature and form of cognitive operations. Accordingly, we did not study the possible failures in mentalisation or deficiencies in integrative operations.

\section{Emotion Recognition}

Theme 5. Emotion Recognition According to our findings, patients would identify not only facial mimic but others' expressive gestures as well. They attempted to form a comprehensive picture based on expressive motions while identifying emotions (Node 8: "Expression of Emotions" built from the categories of "Gesture" and "Facial Expression", and Node 9: "Naming Emotional States").

\section{Patient 6: "It must be something painful." \\ Patient 4: “I don't think so. He's strongly concentrat- ing. He's singing... his mouth is open. He isn't cov- ering his face... just kind of burying his face in his hands...I mean with bowed head. I mean... like raising his hands to his face because of pain. His eyes are closed. He's concentrating. I would rather say that he may be feeling something full of passion." (Cycle 2, Module 4)}

\section{Social Perception}

Themes 6 and 7. Non-Social Context and Social Context In addition to identifying social cues in a direct manner, patients also used the available contextual information where it was facilitated by MCT. Besides, the identified categories and nodes that built up these themes show that patients could identify non-social elements of the context, like externals of the characters seen in the training stimuli or visual elements of the context, then used them as a crutch while they were searching for social cues (Node 10: “Objects Surrounding 
the Social Context" built up from the categories of "Naming" and "Externals").

Patient 2: "I think the right solution is A."

Trainer: "Why do you think it is A?"

Patient 2: "Because there are notes in the pictures. Music. There is a bed. A bedroom. Yes. The man is wearing pyjamas. That means it is early morning. Definitely. The man is wearing pyjamas, and he's angry. Angry because of the music. He cannot sleep because of the early morning music in the street. So he's throwing eggs at the people playing music in the street. He's taking revenge." (Cycle 2, Module 4)

Sometimes patients made assumptions regarding the (social) background of the other person. In some cases, these hypotheses were useful in identifying social cues and context ["He's a rapper." (Cycle 1, Module 6); "They aren't Hungarian children because they are learning Hungarian in the picture. They are foreign children sent by their parents abroad to a summer school." (Cycle 2, Module 6)], while at other times this tendency to formulate hypotheses about other persons could also result in the common cognitive bias in patients with schizophrenia, i.e., the jumping-to-conclusions bias (Freeman et al., 2006) ("I think he's an alcoholic or a drug addict... I can see tattoos and piercing there. He's smoking a cigarette... He's unemployed, does whatever he wants." (Cycle 2, Module 6). (Nodes 11 and 12: "Ideas about the Social Context" and "Social Cues" built up from the categories of "Social Classification", "Background", and "Cues of a Situation".)

\section{Further Themes that Emerged}

Theme 8. Inappropriate Verbalisation. A few but pronounced inappropriate verbal contents were found in the transcripts of the group sessions, which were inadequate contents not fitting the context of the ongoing conversation; therefore, they were not suitable in the given social situation (Node 13).

In order to make this more comprehensible, one of our patients' words are cited:

[Emotion recognition is just being discussed in the group. Group members are trying to identify the possible emotional state of a young lady in a picture.]

Patient 7: "By the way, I have a book in German. Its title is Aila. There is a wolf, a horse, a hunter, and his wife. It's a thick book, has almost 600 pages.
What would it cost to have it translated? Would it be expensive?" (Cycle 1, Module 4)

Theme 9. Illness As the training process progressed, group members shared their experiences about the illness more and more often (Nodes 14 and 15: "Illness" and "Stigma" built from the categories of "Illness", "Medication", "Symptoms", and "Stigma"). They referred to their recent symptoms and difficulties they were struggling with. The group discussed the importance of taking medications - this was something we considered really notable knowing how problematic the adherence of patients with schizophrenia is (Byerly et al., 2007). The strange and weird experiences gained in the acute episodes of the illness became easier to share during the training. Patients reported odd hallucinations, illusions, fears rooted in delusional beliefs, as well as the difficulties of being resident in a psychiatry department.

Group members discussed their fears of being stigmatised by the society, and the difficulties of being stigmatised by themselves (it is important to note here again that the extra module of MCT for stigmatisation was not used in the studied groups).

Theme 10. Training Understandably, we found many verbal manifestations with contents referring to the tasks of the training and the training itself. Because the training is built up in a structured way, with many tasks formulated in the form of a multiple-choice questionnaire, a lot of simple answers ("I think it's B! ") or uncertain responses were identified ("B or C? I don't know. ") (Node 16: "Response" with the categories of "Response" and "Uncertainty of Response"). In many cases, patients verbalised the aids they used simply to get closer to the answer, such as the subjective feeling of lack of information ("It cannot be ascertained. Further information is needed. ") (Node 17: "Aids to Solve Training Tasks").

Furthermore, patients sometimes disclosed their opinion regarding the training and training material ("I like this type of task."; "The drawings are not good. What is it? Can you make it out?"), and we could also gain some information regarding the subjective applicability of the training ("I find it useful."; "Well, I've been using it ever since.") (Node 18: "Opinions on the Applicability of the Training").

\section{Discussion}

There are only a few qualitative studies focusing on metacognitive or social cognitive functions in patients with schizophrenia (e.g., Lysaker et al., 2015b). However, to the best of our knowledge, metacognitive and social cognitive 
operations performed while solving targeted MCT tasks have not been studied with the help of qualitative methodology yet.

We applied inductive content analysis to gain a detailed picture of the verbalisations of patients with schizophrenia, which patients produced while solving the tasks of the theory of mind modules of MCT. We assume that verbal contents reflect the cognitive operations behind them (Brown \& Lenneberg, 1954); therefore, they can serve as an important material for the study of social cognitive and metacognitive operations. A growing body of evidence suggests the presence of metacognitive and social cognitive impairment in schizophrenia (e.g., Lysaker et al., 2014; Penn et al., 2008), which underlines the importance of a more detailed understanding of these functions.

As a result of our content analysis, we have built a five-level hierarchical structure of the verbal contents of patients with schizophrenia in a bottom-up way. At the lower levels are the fine-grained and detailed building blocks of cognitive operations. Above these are the subdomains of social cognition - such as emotion recognition, theory of mind, and social perception - and metacognition - such as self-reflection and understanding others' minds. At the top of the hierarchy are metacognition and social cognition. After comparing the obtained hierarchical structure with the literature of the topic, which is mainly derived from quantitative research, we found a high degree of fit between our results and the information subtracted from literature, with some cases letting us draw new important conclusions.

Metacognition We considered verbal contents to be manifestations of metacognitive processing at points where monitoring and control of operations or signs of awareness of one's own cognitive contents could be detected. Patients of the studied MCT groups monitored their own mental state and that of others. They showed self-reflection, i.e., they were somewhat aware of their internal functioning (Theme 2). We considered these verbal contents as manifestations of the subdomain of "Self-Reflection", while contents reflecting the monitoring and understanding of others' mental states (Theme 1) were considered as productions of the subdomain called "Understanding Others' Mind" (Lysaker et al., 2005, 2007). Participants recognised when other group members had different perspectives, and overruled their own viewpoint in many cases. During the bottom-up analysis, these verbal contents were organised into Theme 1: "Knowledge of Cognitive Perspectives", which partly reflects the operations of the above-mentioned subdomain. At the same time, the processing of the metacognitive subdomain of "Decentration" is implied in these verbalisations as well (e.g., categories of "Different Perspectives", or "Agreement with Others' Perspectives").
Lysaker et al. (2013b) suggest that metacognition can be considered as a spectrum of discrete to synthetic monitoring and controlling mental activities, and the synthetisation of metacognitive experiences and knowledge allows us to form comprehensive representations of the self and others. It is important to take into consideration that in the current analysis the correctness of patients' extrapolations was not studied, although the incorrect functioning of these operations can serve as a basis for metacognitive failures in patients with schizophrenia that may result in disorganisation, impaired sense of agency and self-monitoring, and lack of insight into one's own and others' cognitions and internal states (Koren et al., 2006).

In addition, no signs of awareness of consequences or effects of the concluded social phenomena on further social interactions or adjustment were detected, although the training would enable that. In other words, we have not found any verbal contents to be considered as manifestations of the operation of the subdomain of "Mastery". Consequently, it was not discussed in the group that the revealed aspects of one's own and others' mental operations can contribute to the success or failure of social functioning and adjustment, or the cognitive perspectives can have an effect on one's behaviour and subsequently on social relationships. However, without being aware of the consequences it is hardly possible to integrate all the knowledge rooted in metacognitive operations into comprehensive representations of the self and others, which can contribute to the occurrence and persistence of delusional ideation and poor social functioning (Dimaggio et al., 2009; Lysaker et al., 2005). However, our results are limited to the context of the studied modules. A content analysis on other modules, which focus more explicitly on metacognitive functions, might yield different results, as there are data on the effects of MCT on insight (Lopez-Morinigo et al., 2020a, b).

Social Cognition Although the subdomains of social cognition have been grouped in several ways, we decided to compare the results of our content analysis to the classification done by Pinkham et al. (2014). Our patients deduced ideas about their own and others' internal states and characteristics, which we considered as simple first-order ToM operations (Brüne, 2005; Premack \& Woodruff, 1978). This is reflected in Theme 3: "Ideas about Others' Internal Characteristics". In addition, they realised that another person can have ideas about the mental state of a third person (e.g., Node 7: "Knowledge about Others' Ideas Regarding a Third Part of the Context"), which is a higher-ordered ToM operation (Wimmer \& Perner, 1983). The ToM is one of the subdomains of social cognition (Pinkham et al., 2014); therefore, we considered these operations to be signs of social cognitive operations. The impairment of ToM in schizophrenia is well-documented (e.g., Abu-Akel, 1999; Firth \& 
Corcoran, 1996; Herold et al., 2002; Kelemen et al., 2019). Our current study is not suited to detect errors in ToM operations, it only examines their manifestations. In addition, we registered that patients tend to form intuitive ideas about essential internal characteristics or background information related to others. Although our aim was not the study of the correctness of verbal contents, we cannot neglect the tendency of patients to make intuitive judgments based on few pieces of information. This reduced data gathering based on intuitive judgements of others' internal states and social background without further evidence may be the manifestation of the jumping-to-conclusions bias (Freeman et al., 2006; Garety et al., 1991). This is a common attributional bias in patients with schizophrenia, which may lead to false judgments and incidence of delusional symptoms (McLean et al., 2017).

When inferring others' emotional states (Theme 5), our patients with schizophrenia explicitly relied not only on facial expressions but also on the expressive gestures of the other person (Node 8). Although the literature of emotion recognition, a further subdomain of social cognition (Pinkham et al., 2014) considers facial expressions, prosody, and gestures as essential domains of emotion identification (Mandal et al., 1998), facial expressions seem to be overrepresented, while gestures seem to be underrepresented in research and remediation methods aimed at the improvement of emotion recognition of patients with schizophrenia (Vass et al., 2018). Our results suggest that future research and training should focus more on expressive movements.

Our group members looked actively for information about social clues and roles (Themes 6 and 7), i.e., information rooted in operations of the social cognitive subdomain called social perception (Pinkham et al., 2014). They sought contextual information, which they later used for developing ideas about others minds, and building representations of other persons. This suggests that subfunctions of social cognition like social perception and ToM are mutually supporting processes. Our findings on looking for economic cues contradict literature, showing that patients with schizophrenia fail to use contextual information (Stratta et al., 1999, 2000). It is important to note here that the extensive looking for non-social and social contextual information can be considered to result from guided remediation, and the current study is not fit to evidence that patients could mobilise this ability even without facilitation.

As additional findings, besides the clear metacognitive and social cognitive operations some further important themes were identified. As mentioned above, literature shows that patients with schizophrenia often fail to match internal contents to the context of the external reality (Stratta et al., 1999, 2000). The few but pronounced inadequate verbal contents in the transcripts of group sessions are perfect proof of this matching failure; we suppose that the manifestation of impairments of metacognitive control and regulation can be observed in these inappropriate contents (Theme 8).

Another important finding of our study is related to the verbal expressions on the importance of taking medications, the shared experiences regarding the symptoms of the illness, as well as the painful realisation of stigmatisation (Theme 9). The mentioned verbal contents can be considered valuable because these contents cannot be formulated without at least minimum awareness of the illness, e.g., without metacognitive monitoring (David et al., 2012). In addition, sharing this content can reduce the burden of being ill, contribute to the development of a more adaptive coping strategy regarding the illness, and strengthen adherence not only to the training but the administered psychiatric treatment as well. It is important to mention here that although MCT has an additional module for stigmatisation, it was not used in the examined groups.

As Lysaker and his co-workers (Lysaker et al., 2013a) suggest, patients with schizophrenia are not merely passive sufferers of biological and social events, but they actively interpret what is happening in and around them. Our results on the rich background of metacognitive and social cognitive operations confirm this statement.

It could be concluded from our results that our five-level hierarchy, which is consistent with literature findings, merely reflects the fact that MCT has been developed in accordance with theoretical knowledge. However, we suggest that the results of the content analysis would not be in line with theoretical knowledge if cognitive functioning had been actually carried out along other pathways, or if our study participants had not been, at least partially, able to perform these operations, even if with mistakes.

\section{Strengths and Limitations}

To the best of our knowledge, this is the first qualitative study carried out on the verbal contents of MCT groups, and one of the few qualitative studies on metacognition and social cognition in schizophrenia. The recent study was able to explore the complex phenomena and also the deeper layers of cognitive operations.

At the same time, our study has several limitations. First, participants of the two examined groups were all outpatients in remission. The qualitative study of the social cognitive and metacognitive processing of patients in other stages of the illness may provide further valuable information. Second, all of our patients were employed at the time of the study. In other words, our group members showed better functional abilities than it is usually common in patients with schizophrenia. Repeating the study in patients with a wider range of demographic data might result in additional 
findings. This means that the present results are not generalisable to the entire population of persons with schizophrenia.

Furthermore, the current study was not designed to prove whether participants of MCT groups can transfer the identified metacognitive and social cognitive operations to reallife situations.

Also, we have not studied the rightness of the statements and judgments of the patients; our aim was to examine the nature of their cognitive operations. A study of the correctness of the verbal contents could provide a more nuanced picture of metacognitive and social cognitive functions in patients with schizophrenia.

Future research should analyse the verbal contents of patients with schizophrenia not receiving MCT to prove that these results are related not only to the training. Alternatively, by studying the verbal contents of individuals without psychiatric diagnoses or individuals diagnosed with other conditions than schizophrenia, it would be possible to determine with certainty how valid our present results are for metacognitive and social cognitive functions in general, and how specific they are in schizophrenia.

We consider it important to take all these limitations into account when interpreting our results, as they may reduce the external validity of our research.

\section{Conclusions}

To sum up, we managed to gain a comprehensive picture of cognitive processing in patients with schizophrenia through their verbal manifestations produced while solving MCT tasks. The training provided scope for the emergence of metacognitive and social cognitive operations. The inductive qualitative study design resulted in a five-level hierarchical structure fairly consistent with current literature data.

According to our findings, patients mobilised metacognitive and social cognitive functions, they inferred their own and others' mental states and characteristics, and in the course of identifying emotions they relied heavily on expressive movements in addition to mimic. They sought contextual information and integrated it into their judgements. However, patients have not expressed that they realised the possible consequences of the inferred social phenomena on further social interactions. They tended to jump to conclusions regarding others' mental states and background, and sometimes failed to match internal contents to external reality. These elements can play a crucial role in impaired social functions, sense of self and development, and maintenance of delusional ideas and hallucinations in patients with schizophrenia. Even if patients are able to carry out metacognitive and social cognitive operations, without them being aware of the consequences and comparing the internal results of these operations to external reality, metacognition and social cognition cannot work properly in patients with schizophrenia.

Authors' Contributions Zita Fekete: prepared the manuscript; designed the study; analysed and interpreted data; made contributions to the acquisition of data.

Edit Vass: made contributions to the conception of the work and to the interpretation of data.

Martina Farkas-Pócs: made substantial contributions to the acquisition of data.

Ramóna Balajthy: made substantial contributions to the acquisition of data.

Ildikó Szabó Kuritárné: revised the manuscript critically for important intellectual content; made contributions to the interpretation of data.

Funding Open access funding provided by University of Debrecen. This research has not received any specific grant from funding agencies in the public, commercial, or not-for-profit sectors.

Data Availablity The data that support the findings of this study are available on request from the corresponding author. The data are not publicly available due to language restrictions.

Code Availibility Not applicable.

\section{Declarations}

Ethics approval Ethical approval was granted by the Hungarian Scientific Ethical Committee for Research, and the study got approval number 42520-2/2018/EKU.

Consent to patricipate and for publication All participants signed an informed consent form.

Conflicts of Interest The authors report no conflict of interest.

Open Access This article is licensed under a Creative Commons Attribution 4.0 International License, which permits use, sharing, adaptation, distribution and reproduction in any medium or format, as long as you give appropriate credit to the original author(s) and the source, provide a link to the Creative Commons licence, and indicate if changes were made. The images or other third party material in this article are included in the article's Creative Commons licence, unless indicated otherwise in a credit line to the material. If material is not included in the article's Creative Commons licence and your intended use is not permitted by statutory regulation or exceeds the permitted use, you will need to obtain permission directly from the copyright holder. To view a copy of this licence, visit http://creativecommons.org/licenses/by/4.0/.

\section{References}

Abu-Akel, A. (1999). Impaired theory of mind in schizophrenia. Pragmatics and Cognition, 7(2), 247-282. https://doi.org/10.1075/ pc.7.2.02abu.

Arnon-Ribenfeld, N., Hasson-Ohayon, I., Lavidor, M., Atzil-Slonim, D., \& Lysaker, P. H. (2017). The association between metacognitive abilities and outcome measures among people with 
schizophrenia: A meta-analysis. European Psychiatry, 46, 33-41. https://doi.org/10.1016/j.eurpsy.2017.08.002.

Brown, R. W., \& Lenneberg, E. H. (1954). A study in language and cognition. The Journal of Abnormal and Social Psychology, 49(3), 454-462. https://doi.org/10.1037/h0057814.

Brüne, M. (2005). „Theory of mind” in schizophrenia: A review of the literature. Schizophrenia Bulletin, 31(1), 21-42. https://doi.org/ 10.1093/schbul/sbi002.

Byerly, M. J., Nakonezny, P. A., \& Lescouflair, E. (2007). Antipsychotic medication adherence in schizophrenia. Psychiatric Clinics of North America, 30(3), 437-452. https://doi.org/10.1016/j.psc. 2007.04.002.

David, A. S., Bedford, N., Wiffen, B., \& Gilleen, J. (2012). Failures of metacognition and lack of insight in neuropsychiatric disorders. Philosophical Transactions of the Royal Society of London. Series B, Biological Sciences, 367(1594), 1379-1390. https://doi.org/10. 1098/rstb.2012.0002.

Dimaggio, G., Vanheule, S., Lysaker, P. H., Carcione, A., \& Nicolò, G. (2009). Impaired self-reflection in psychiatric disorders among adults: A proposal for the existence of a network of semi independent functions. Consciousness and Cognition, 18(3), 653-664. https://doi.org/10.1016/j.concog.2009.06.003.

Eichner, C., \& Berna, F. (2016). Acceptance and efficacy of metacognitive training (MCT) on positive symptoms and delusions in patients with schizophrenia: A meta-analysis taking into account important moderators. Schizophrenia Bulletin, 42(4), 952-962. https://doi.org/10.1093/schbul/sbv225

Fioravanti, M., Carlone, O., Vitale, B., Cinti, M. E., \& Clare, L. (2005). A meta-analysis of cognitive deficits in adults with a diagnosis of schizophrenia. Neuropsychology Review., 15(2), 73-95. https:// doi.org/10.1007/s11065-005-6254-9.

Firth, C. D. (2015). The cognitive neuropsychology of schizophrenia: Classic edition (1st ed.). Psychology Press. https://doi.org/10. 4324/9781315749174.

Firth, C. D., \& Corcoran, R. (1996). Exploring 'theory of mind' in people with schizophrenia. Psychological Medicine, 26(3), 521-530. https://doi.org/10.1017/s0033291700035601.

Flavell, J. H. (1979). Metacognition and cognitive monitoring. A new area of cognitive- developmental inquiry. American Psychologist, 43(10), 906-911. https://doi.org/10.1037/0003-066X.34.10.906.

Freeman, D., Garety, P., Kuipers, E., Colbert, S., Jolley, S., Fowler, D., Dunn, G., \& Bebbington, P. (2006). Delusions and decision-making style: Use of the need for closure scale. Behaviour Research and Therapy, 44(8), 1147-1158. https://doi.org/10.1016/j.brat. 2005.09.002.

Garety, P. A., Hemsley, D. R., \& Wessely, S. (1991). Reasoning in deluded schizophrenic and paranoid patients. The Journal of Nervous and Mental Disease, 179(4), 194-201. https://doi.org/ 10.1097/00005053-199104000-00003.

Green, M. F., Penn, D. L., Bentall, R., Carpenter, W. T., Gaebel, W., Gur, R. C., Kring, A. M., Park, S., Silverstein, S. M., \& Heissen, R. (2008). Social cognition in schizophrenia: An NIMH workshop on definitions, assessment, and research opportunities. Schizophrenia Bulletin, 34(6), 1211-1220. https://doi.org/10.1093/schbul/sbm145.

Herold, R., Tényi, T., Lénárd, K., \& Trixler, M. (2002). Theory of mind deficit in people with schizophrenia during remission. Psychological Medicine, 32(6), 1125-1129. https://doi.org/10.1017/ s0033291702005433.

Hofer, A., Benecke, C., Edlinger, M., Huber, R., Kemmler, G., Rettenbacher, M. A., Schleich, G., \& Fleischhacker, W. W. (2009). Facial emotion recognition and its relationship to symptomatic, subjective, and functional outcomes in outpatients with chronic schizophrenia. European Psychiatry, 24(1), 27-32. https://doi.org/10. 1016/j.eurpsy.2008.06.008.
Hsieh, H.-F., \& Shannon, S. E. (2005). Three approaches to Qualitative Content Analysis. Qualitative Health Research, 15(9), 12771288. https://doi.org/10.1177/1049732305276687.

Irani, F., Seligman, S., Kamath, V., Kohler, C., \& Gur, R. C. (2012). A meta-analysis of emotion perception and functional outcomes in schizophrenia. Schizophrenia Research, 137(1-3), 203-211. https://doi.org/10.1016/j.schres.2012.01.023.

Kelemen, O., Máttyássy, A., \& Kéri, Sz. (2019). Improvement of theory of mind in schizophrenia: A 15-year follow-up study. Psychology, 1(1), 420-428. https://doi.org/10.3390/psych1010032.

Koren, D., Seidman, L. J., Goldsmith, M., \& Harvey, P. D. (2006). Real-world cognitive - and metacognitive- dysfunction in schizophrenia: A new approach for measuring (and remediation) more "right stuff." Schizophrenia Bulletin, 32(2), 310-326. https://doi. org/10.1093/schbul/sbj035.

Liu, Y.-C., Tang, C.-C., Hung, T.-T., Tsai, P.-C., \& Lin, M.-F. (2018). The efficacy of metacognitive training for delusions in patients with schizophrenia: A meta-analysis of randomized controlled trials informs evidence-based practice. Worldviews on Evidence Based Nursing, 15(2), 130-139. https://doi.org/10.1111/wvn. 12282.

Lopez-Morinigo, J., Ajnakina, O., Martínez, A., Escobedo-Aedo, P., Ruiz-Ruano, V., Sánchez Alonso, S., Mata-Iturralde, L., MuñozLorenzo, L., Bara-García, E., \& David, A. (2020). Can metacognitive interventions improve insight in schizophrenia spectrum disorders? A systematic review and meta-analysis. Psychological Medicine, 50(14), 2289-2301. https://doi.org/10.1017/S0033 291720003384.

Lysaker, P. H., Carcione, A. A., Dimaggio, G. G., Johannesen, J. K., Nicol, G. G., Procacci, M. M., \& Semerari, A. (2005). Metacognition amidst narratives of self and illness in schizophrenia: Associations with neurocognition, symptoms, insight and quality of life. Acta Psychiatria Scandinavica, 112(1), 64-71. https://doi. org/10.1111/j.1600-0447.2005.00514.x.

Lysaker, P. H., Dimaggio, G., Buck, K. D., Carcione, A., \& Nicolò, G. (2007). Metacognition within narratives of schizophrenia: Associations with multiple domains of neurocognition. Schizophrenia Research, 39(1-3), 278-287. https://doi.org/10.1016/j.schres. 2007.02.016.

Lysaker, P. H., Vohs, J. L., Ballard, R., Fogley, R., Salvatore, G., Popolo, R., \& Dimaggio, G. (2013a). Metacognition, self-reflection and recovery in schizophrenia. Future Neurology, 8(1), 103-115. https://doi.org/10.2217/fnl.12.78.

Lysaker, P. H., Bob, P., Pec, O., Hamm, J., Kukula, M., Vohs, J., Popolo, R., Salvatore, G., \& Dimaggio, G. (2013b). Synthetic metacognition as a link between brain and behavior in schizophrenia. Translational Neuroscience, 4(3), 368-377. https://doi.org/10. 2478/s13380-013-0131-4.

Lysaker, P. H., Gumley, A., Luedtke, B., Buck, K. D., Ringer, J. M., Olesek, K., Kukla, M., Leonhardt, B. L., Popolo, R., \& Dimaggio, G. (2013c). Social cognition and metacognition in schizophrenia: Evidence of their independence and linkage with outcomes. Acta Psychiatrica Scandinavica, 127(3), 239-247. https://doi.org/10. 1111/acps.12012.

Lysaker, P. H., Dimaggio, G. C., Brüne, M. (2014). Social Cognition and metacognition in schizophrenia. Psychopathology and treatment approaches (1st ed.). Academic Press.

Lysaker, P. H., Kukla, M., Dubreucq, J., Gumley, A., McLeod, H., Vohs, J. L., Buck, K. D., Minor, K. S., Luther, L., Leonhardt, B. L., Belanger, E. A., Popolo, R., \& Dimaggio, G. (2015a). Metacognitive deficits predict future levels of negative symptoms in schizophrenia controlling for neurocognition, affect recognition, and self-expectation of goal attainment. Schizophrenia Research, 168(1-2), 267-272. https://doi.org/10.1016/j.schres.2015.06.015. 
Lysaker, P. H., Kukla, M., Belanger, E., White, D. A., Buck, K. D., Luther, L., Firmin, R. L., \& Leonhardt, B. L. (2015b). Individual psychotherapy and changes in self-experience in schizophrenia: A qualitative comparison of clients in metacognitively focused and supportive psychotherapy. Psychiatry, 78(4), 305-316. https://doi. org/10.1080/00332747.2015.1063916.

Lopez-Morinigo, J., Ajnakina, O., Martínez, A., Escobedo-Aedo, P., Ruiz-Ruano, V., Sánchez Alonso, S., Mata-Iturralde, L., MuñozLorenzo, L., Bara-García, E., \& David, A. (2020b). Can metacognitive interventions improve insigh in schizophrenia spectrum disorders? A systematic review and meta-analysis. Psychological Medicine, 50(14), 2289-2301. https://doi.org/10.1017/S0033 291720003384.

Mandal, M. K., Pandey, R., \& Prasad, A. B. (1998). Facial expressions of emotions and schizophrenia: A review. Schizophrenia Bulletin, 24(3), 399-412. https://doi.org/10.1093/oxfordjournals. schbul.a033335.

Mays, N., \& Pope, C. (1995). Qualitative research: Rigour and qualitative research. British Medical Journal, 311, 109-112. https://doi. org/10.1136/bmj.311.6997.109.

McGrath, J., Saha, S., Chant, D., \& Welham, J. (2008). Schizophrenia: A concise overview of incidence, prevalence, and mortality. Epidemiologic Reviews, 30(1), 67-76. https://doi.org/10.1093/ epirev/mxn001.

McLean, B. F., Mattiske, J. K., \& Balzan, R. P. (2017). Association of the jumping to conclusions and evidence integration biases with delusions in psychosis: A detailed meta-analysis. Schizophrenia Bulletin, 43(2), 344-354. https://doi.org/10.1093/schbul/sbw056.

Moritz, S., \& Woodward, T. S. (2007). Metacognitive training in schizophrenia: From basic research to knowledge translation and intervention. Current Opinion in Psychiatry, 20(6), 619-625. https:// doi.org/10.1097/YCO.0b013e3282f0b8ed.

Nelson, T. O. (1996). Consciousness and metacognition. American Psychologist, 51(2), 102-116. https://doi.org/10.1037/0003-066X. 51.2.102.

Penn, D. L., Ritchie, M., Francis, J., Combs, D., \& Martin, J. (2002). Social perception in schizophrenia: The role of context. Psychiatry Research, 109(2), 149-159. https://doi.org/10.1016/S01651781(02)00004-5.

Penn, D. L., Sanna, L. J., \& Roberts, D. L. (2008). Social cognition in schizophrenia: An overview. Schizophrenia Bulletin, 34(3), 408-411. https://doi.org/10.1093/schbul/sbn014.

Pinkham, A. E., Penn, D. L., Green, M. F., Buck, B., Healey, K., \& Harves, P. D. (2014). The social cognition psychometric evaluation study: Results of the expert survey and RAND panel. Schizophrenia Bulletin, 40(4), 813-823. https://doi.org/10.1093/schbul/ sbt081.
Premack, D., \& Woodruff, G. (1978). Does the chimpanzee have a theory of mind? The Behavioral and Brain Sciences, 4(4), 515-426. https://doi.org/10.1017/S0140525X00076512.

Renz, S. M., Carrington, J. M., \& Badger, T. A. (2018). Two Strategies for qualitative content analysis: An intramethod approach to triangulation. Qualitative Health Research, 28(5), 824-831. https:// doi.org/10.1177/1049732317753586.

Savla, G. N., Vella, L., Armstrong, C. C., Penn, D. L., \& Twamley, E. W. (2013). Deficits in domains of social cognition in schizophrenia: A meta-analysis of the empirical evidence. Schizophrenia Bulletin, 39(5), 979-992. https://doi.org/10.1093/schbul/sbs080.

Stratta, P., Daneluzzo, M., Bustini, P. L., Prosperini, P. L., \& Rossi, A. (1999). Schizophrenic patients use context-independent reasoning more than context-dependent reasoning as measured by the Cognitive Bias Task (CBT): A controlled study. Schizophrenia Research, 37(1), 45-51. https://doi.org/10.1016/S0920-9964(98) 00132-7.

Stratta, P., Daneluzzo, M., Bustini, P. L., Prosperini, P. L., \& Rossi, A. (2000). Processing of context information in schizophrenia: Relation to clinical symptoms and WCST performance. Schizophrenia Research, 44(1), 57-67. https://doi.org/10.1016/S0920-9964(99) 00142-5.

Tong, A., Sainsbury, P., \& Craig, J. (2007). Consolidated criteria for reporting qualitative research (COREQ): A 32-item checklist for interviews and focus groups. International Journal for Quality in Health Care, 19(6), 349-357. https://doi.org/10.1093/intqhe/ mzm042.

Valle, H., Massaro, D., Castelli, I., \& Maschetti, A. (2015). Theory of mind development in adolescence and early adulthood: The growing complexity of recursive thinking ability. Europe's Journal of Psychology, 11(1), 112-124. https://doi.org/10.5964/ejop. v11i1.829.

van Os, J., \& Kapur, S. (2009). Schizophrenia. The Lancet, 374(9690), 635-645. https://doi.org/10.1016/S0140-6736(09)60995-8.

Vass, E., Fekete, Z., Simon, V., \& Simon, L. (2018). Interventions for the treatment of theory of mind deficits in schizophrenia: Systematic literature review. Psychiatry Research, 267, 37-47. https:// doi.org/10.1016/j.psychres.2018.05.001.

Wimmer, H., \& Perner, J. (1983). Beliefs about beliefs: Representation and constraining function of wrong beliefs in young children's understanding of deception. Cognition, 13(1), 103-128. https:// doi.org/10.1016/0010-0277(83)90004-5.

Publisher's Note Springer Nature remains neutral with regard to jurisdictional claims in published maps and institutional affiliations. 